This item was submitted to Loughborough's Research Repository by the author.

Items in Figshare are protected by copyright, with all rights reserved, unless otherwise indicated.

\title{
Improving long term driving comfort by taking breaks - How break activity affects effectiveness
}

PLEASE CITE THE PUBLISHED VERSION

http://dx.doi.org/10.1016/j.apergo.2017.05.008

PUBLISHER

(C) Elsevier

VERSION

AM (Accepted Manuscript)

\section{PUBLISHER STATEMENT}

This work is made available according to the conditions of the Creative Commons Attribution-NonCommercialNoDerivatives 4.0 International (CC BY-NC-ND 4.0) licence. Full details of this licence are available at: https://creativecommons.org/licenses/by-nc-nd/4.0/

\section{LICENCE}

CC BY-NC-ND 4.0

\section{REPOSITORY RECORD}

Sammonds, George M., Neil J. Mansfield, and Mike Fray. 2019. "Improving Long Term Driving Comfort by Taking Breaks - How Break Activity Affects Effectiveness". figshare. https://hdl.handle.net/2134/25871. 


\title{
IMPROVING LONG TERM DRIVING COMFORT BY TAKING BREAKS - HOW BREAK ACTIVITY AFFECTS EFFECTIVENESS
}

\author{
George M Sammonds ${ }^{1,2}$, Neil J Mansfield ${ }^{1,2,3}$ \& Mike Fray ${ }^{2}$ \\ 1. Dyson School of Design Engineering, Imperial College London, SW7 2AZ, UK \\ 2. Loughborough Design School, Loughborough University, LE11 3TU, UK \\ 3. Department of Engineering, Nottingham Trent University, NG11 8NS, UK
}

\begin{abstract}
During long duration journeys, drivers are encouraged to take regular breaks. The benefits of breaks have been documented for safety; breaks may also be beneficial for comfort. The activity undertaken during a break may influence its effectiveness. Volunteers completed 3 journeys on a driving simulator. Each 130 minute journey included a 10 minute break after the first hour. During the break volunteers either stayed seated, left the simulator and sat in an adjacent room, or took a walk on a treadmill. The results show a reduction in driver discomfort during the break for all 3 conditions, but the effectiveness of the break was dependent on activity undertaken. Remaining seated in the vehicle provided some improvement in comfort, but more was experienced after leaving the simulator and sitting in an adjacent room. The most effective break occurred when the driver walked for 10 minutes on a treadmill. The benefits from taking a break continued until the end of the study (after a further hour of driving), such that comfort remained the best after taking a walk and worst for those who remained seated. It is concluded that taking a break and taking a walk is an effective method for relieving driving discomfort.
\end{abstract}

\section{Keywords}

Driving comfort, automotive, taking breaks, seating

\section{Background}

When drivers stop at highway service stations they can be observed undertaking different activities. Some choose to remain seated in their vehicles, possibly performing 'mobile office' tasks; many choose to walk to a café and sit for a few minutes drinking a coffee; some might take a pet dog for a short walk or play active games with children (e.g. Sammonds, 2016). It is reasonable to question whether the choice of task affects the effectiveness of taking a break from driving.

The field of driver vehicle ergonomics has, in recent years, placed large emphasis on designing seats for driver comfort. Driver comfort has developed from being considered a luxury to a requirement (Kolich \& Taboun, 2004) and a comfortable seat now plays a crucial 
role in the perception of a vehicle's overall quality (Kyung et al., 2008a, b). As a result, manufacturers have been pursuing more effective methods to improve seat comfort as this is seen as a direct approach to gain an advantage in the market.

Regardless of how well a seat has been designed using today's technologies, the occupant will become uncomfortable after many hours of driving (Mansfield et al., 2015; Sammonds et al., 2017) or travelling as a passenger (Hiemstra-van Mastrigt et al., 2016). When this happens the driver needs to manage their own discomfort and may employ strategies to feel refreshed. One of the methods proposed in order to combat the negative effects of long term driving is to implement breaks into a drive. The benefits of in-seat activities like eating and drinking have been reported for airline travel, but a more effective action is to take a walk around the aircraft cabin (Hiemstra-van Mastrigt et al., 2016). Drivers are encouraged to take breaks when undertaking a long term drive to combat the issues surrounding tiredness and safety (Horne \& Reyner, 1999; Horne \& Reyner, 1995), but breaks from driving may also have a positive impact on driver discomfort. A break from driving provides the driver with the opportunity to alter their posture whilst away from the driving task and in turn, relieves pressure on compressed body parts, increasing blood flow to areas of the body that may be causing discomfort. Ravnik et al. (2008) established that discomfort could be reduced to almost zero during a 15-minute break that followed 100 minutes of driving; suggesting that breaks from driving may have a positive impact on discomfort.

As the vehicle is a dynamic environment, vibration exposure is a key-contributing factor to long-term discomfort experienced by drivers (Mansfield et al., 2014). Breaks from vibration exposure may allow the negative effects of vibration exposure on discomfort to be reduced following the cessation of vibration. Yonekawa et al. (1998) investigated the effects of rest time on Temporary Threshold Shift (TTS) due to intermittent vibration exposure when using hand held tools. The authors proposed rest time of 5 minutes by the Labour Ministry in Japan should be increased to 10 minutes in order to allow for full recovery of TTS.

If the benefits of taking a break from a long-term drive and the associated vibration exposure can be well defined there may be a wide range of implications. The effect of taking a break from whole-body vibration exposure on discomfort is not well documented, although Dunstan et al. (2012) showed reductions in blood glucose and insulin for overweight/obese adults if they took breaks from sitting in a domestic setting. The US 
Nurses Health Study cohort showed that even small levels of activity whilst sitting can be associated with improved health outcomes, and that the most sedentary 'activity' (watching TV) is associated with increases in obesity and type 2 diabetes (Hu et al. 2003). There are many industries where taking breaks could be optimized for effectiveness. For example, drivers operating heavy machinery as part of their job have been known to work throughout the duration of a day with no breaks (Kuijt-Evers et al., 2003), out of choice (e.g. working through a lunch 'hour' so that they can finish work an hour early). Such drivers are exposed to greater magnitudes of vibration when compared to normal road users and if the benefits of taking a break from vibration exposure can be determined, there are potential implications for a range of environments outside of normal road driving.

This paper reports the results of a study that evaluated the effectiveness of taking breaks during a long term drive in order to fully understand how altering the driving posture and cessation of vibration exposure can influence driver discomfort. It aimed to determine these effects both subjectively and objectively via the use of discomfort rating scales and an objective measure of discomfort (Seat Fidgets and Movements) that was shown to be successful in Sammonds et al. (2017).

\section{Methodology}

10 regular drivers (7 males and 3 females) from the local and student population of Loughborough University were recruited to take part in a laboratory experiment. Participants were required to be aged between 18 and 65, and held a UK driving license at the time of participation. Participants completed a health screening questionnaire prior to participation in the study to establish if any had experienced musculoskeletal disorders in the past. Participants with a history of musculoskeletal disorders were excluded from taking part. Participants were naïve to the purpose of the study before taking part and were not informed until debriefed after all sessions were complete. The study was approved by Loughborough University Research Ethics Committee.

Each participant completed three trials each of which occurred on a separate day. Due to practical constraints it was not possible to control for day of week which has been suggested as a confounder (Bazley and Vink, 2016). Each trial had a duration of 130 minutes that consisted of 60 minutes driving, a 10-minute break, followed by a further 60 minutes of driving using a moving-base driving simulator. Participants provided subjective ratings of 
discomfort verbally whilst driving via a 2 part discomfort rating scale at regular time intervals; $0,2,10,20,30,40,50,60,62,70,72,80,90,100,110$ and 120 minutes. Participants were trained in the use of the discomfort rating scales prior to the study; the scales were positioned in the participants' field of view whilst driving. Part one of the discomfort scale focused on local discomfort and part two focused on overall discomfort (Figure 1). Part one includes the 6-point discomfort scale as defined in ISO 2631-1 (1997) and part two utilizes a newly developed discomfort rating scale adapted from the Borg CR100 scale (Borg \& Borg, 2002) and implemented in Mansfield et al. (2015), Sammonds (2016) and Sammonds et al. (2017). One of the main purposes of part one was to act as a primer for part two, i.e. participants were systematically guided through a process of comfort evaluation. Therefore the results reported in this paper focus on the scale in part two. Participants were not interrupted from the driving task to provide discomfort ratings; this was to ensure that the only break from driving occurred in a controlled manner. Prior to participation in the study, participants' age, height and weight were recorded in addition to temperature $\left({ }^{\circ} \mathrm{C}\right)$ and relative humidity $(\% \mathrm{RH})$ of the laboratory (Table 1$)$. 
1. Please use the scale below to choose a number that best represents your level of discomfort in the 5 body areas indicated:

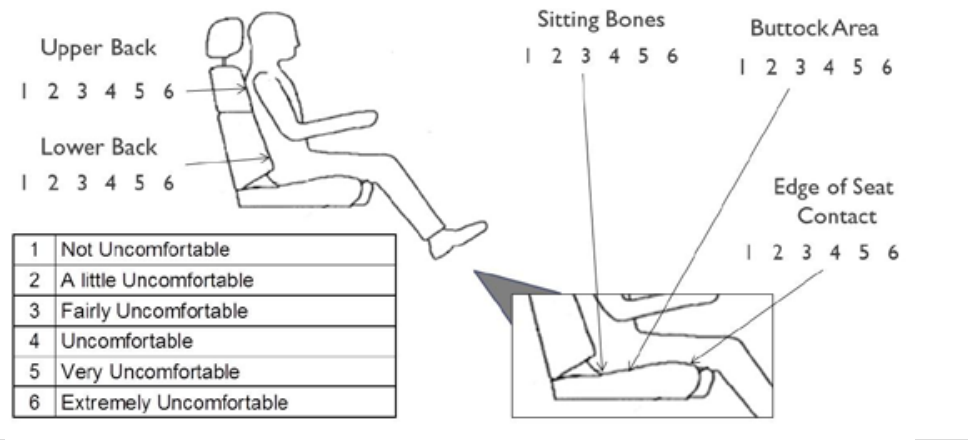

2. Please use the scale to describe your overall level of discomfort:

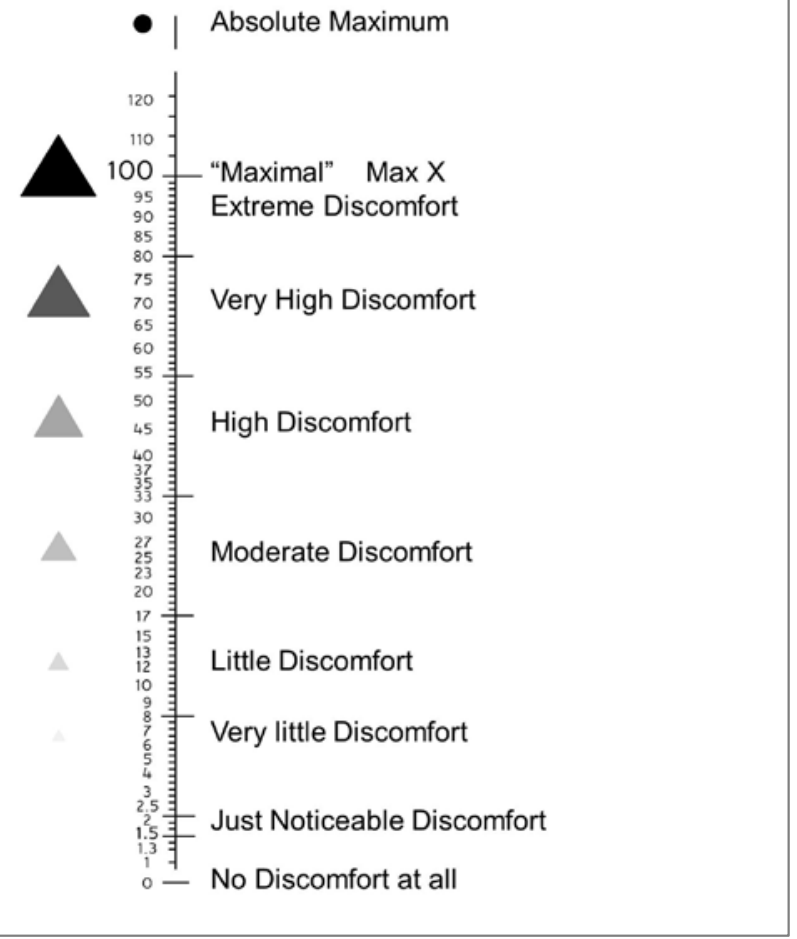

Figure 1: Questionnaire design showing part 1; including the discomfort scale defined in ISO 2631-1 and a description of the body parts analysed, and part 2; including the adapted Borg CR100 scale

(Borg \& Borg, 2002; Sammonds et al., 2016; Sammonds et al., 2017)

Vibration exposure was simulated using a Rexroth Hydraudyne B.V Micro Motion 600-6DOF200MK5 multi-axis vibration simulator (MAVIS) located at Loughborough University. Subjects were exposed to multi-axis vibration with an r.s.s. magnitude of $0.25 \mathrm{~m} / \mathrm{s}^{2}$ r.m.s. The vibration was a replay of 6-dof motion at the floor of a car driving on a rough city road, and was adjusted in magnitude to represent a similar experience to a typical urban drive. 
Table 1: Sample Characteristics

\begin{tabular}{ll}
\hline Characteristic & \\
\hline Number & 10 \\
Gender & 7 male, 3 female \\
Age & $21-35$ Years (mean \pm sd: $25.9 \pm 4.8$ years) \\
Stature & $155-183 \mathrm{~cm}$ (mean $\pm \mathrm{sd}: 176 \pm 8.1 \mathrm{~cm})$ \\
Mass & $43.0-70.5 \mathrm{~kg}$ (mean $\pm \mathrm{sd}: 71.8 \pm 12.1 \mathrm{~kg})$ \\
\hline
\end{tabular}

The driving rig replicated dimensions from a current production vehicle and included the seat and steering wheel (Figure 2). Participants were directed audibly along a standardized route throughout the drive on the driving simulator, via the use of GPS navigation style instructions.

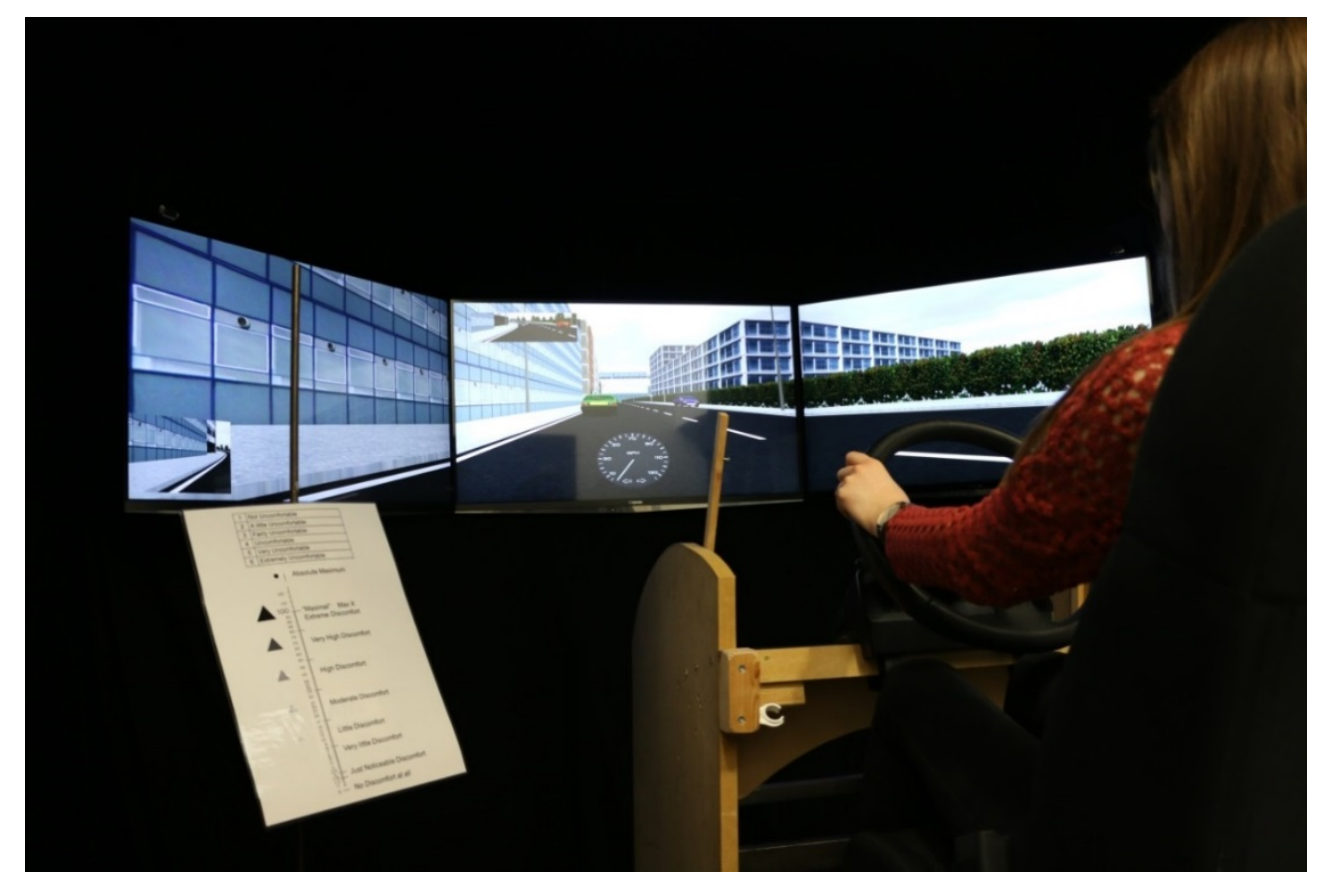

Figure 2: Driving simulator configuration

After 60 minutes of driving on the simulator, participants were required to have a 10-minute break from the driving task. Break types were designed to represent typical types of break that drivers may conduct during a long-term drive and were defined as:

1. Sit - where participants were required to stop the driving task, but remain seated in the car seat. 
2. Walk - where participants were required to stop the driving task, leave the car seat and perform continuous walking on a treadmill maintained at $4 \mathrm{~km} / \mathrm{h}$.

3. Walk \& Sit - where participants were required to stop the driving task, leave the car seat and sit in a standard chair.

After participants had completed the 10-minute break they were required to continue the driving task for a further 60 minutes. The order in which participants completed the 3 break types was randomised across the sample.

In addition to the 2 part subjective ratings of discomfort, Seat Fidgets and Movements (SFMs) were also measured (Sammonds et al. 2017). An SFM is defined as a postural movement that is not related to the driving task and have been shown to correlate with subjective ratings of discomfort. They can be a movement of upper limbs (Type 1), torso (Type 2) or whole body (Type 3). Participants were video recorded to allow the investigator to analyse SFMs post trial and SFMs were recorded in accordance with the methodology outlined in Sammonds et al. (2017). A Microsoft HD (1080p) webcam was positioned at approximately 45 degrees from the subject that provided the experimenter with a full body view of the subject throughout the duration of the trial and allowed the experimenter to analyse and report any SFMs the subject may make. The number of SFMs made by subjects was recorded across 10-minute intervals and accumulatively across the total duration of the trials. Whilst other techniques for assessing comfort were considered, it was not possible to use pressure mats (e.g. Franz, et al. 2012) as they would affect the properties of the seat surface, or more invasive methods such as spinal probes (e.g. Zenk, et al. 2012), as this would have precluded the natural motions required in the walk conditions.

To compare the three conditions and gain a greater understanding of the impact of behavior during breaks, repeated measures ANOVAs were conducted comparing the overall discomfort ratings collected for each condition at 62 and 70 minutes to establish whether a significant difference can be observed $(\alpha=0.05)$. To establish whether a significant difference was observed upon completion of the trial, a repeated measures ANOVA was conducted that compared the overall discomfort ratings recorded at 130 minutes. ANOVA was considered valid for the CR100 data and well-established in its data analysis (e.g. Borg and Borg, 2002). 


\section{Results}

\section{Subjective Overall Discomfort}

The results show that overall discomfort increased with duration of driving for all 3 conditions, supporting the findings of the previous literature (Hiemstra-van Mastrigt et al., 2016; Mansfield et al., 2015; Sammonds et al., 2017; Gyi \& Porter, 1998; Figure 3).

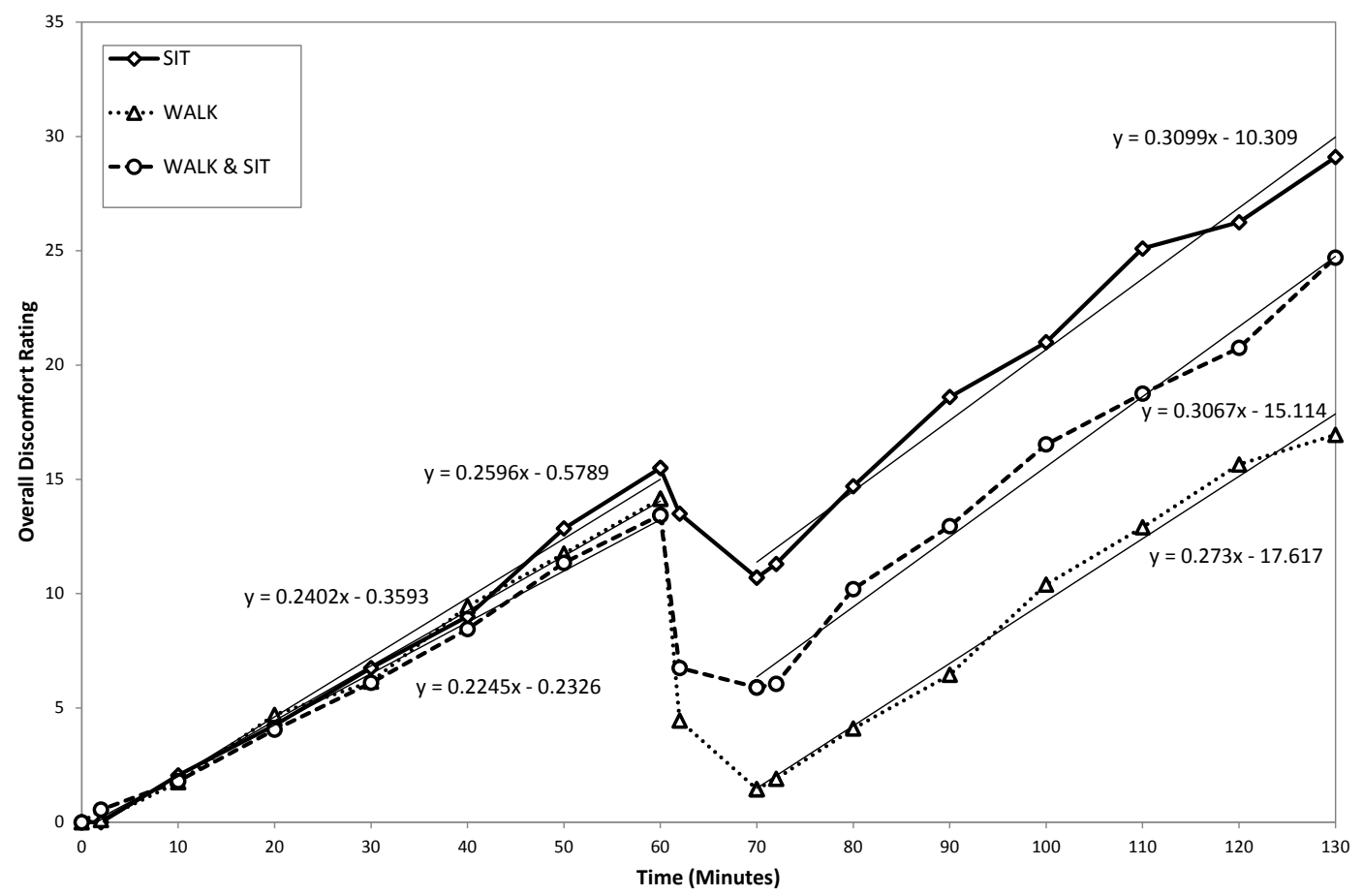

Figure 3: Mean overall discomfort ratings for all conditions over time for all 3 conditions (Sit, Walk, and Walk \& Sit) with regression lines shown from 0-60 minutes and 70-130 minutes.

Data collected during each of the conditions follow a nominally identical trend between 0 60 minutes, as would be expected due to all 3 conditions following the same design up until this point. At 60 minutes the break occurred and for each of the three conditions an acute improvement in comfort was observed. The 'Sit' condition, where subjects did not leave the seat but the driving and vibration stopped, showed the smallest improvement. The 'Walk \& Sit' condition, where subjects left the driving rig and walked to a different chair and sat for 10 minutes, showed better improvements in comfort. The best condition was 'Walk' where participants walked on a treadmill during the 10 minute break from driving.

Upon returning to the driving task, a steady increase in overall discomfort was observed for all 3 conditions where discomfort continued to increase with time at a similar gradient to that observed before the break. There was therefore an offset in discomfort after the break 
dependent on the type of break that had been taken. At the end of the trial, the 'Sit' condition generated the greatest mean overall discomfort rating after 130 minutes of 29.1, followed by the 'Walk \& Sit' condition, 24.7. The 'Walk' condition which recorded the lowest overall discomfort rating, 17.0, after completion of the 130 minute trial.

\section{Objective Seat Fidgets and Movements}

In addition to the subjective discomfort ratings collected, participants' SFM data was collected in order to provide a comparison between subjective discomfort ratings and behavioural data.

The results shown in Figures 4, 5 and 6 show that the mean data recorded for participants' seat fidgets and movements follow a similar trend to those recorded for mean overall discomfort. The results display that a close relationship can be observed between the subjective overall discomfort ratings collected and SFM frequency for each condition with the results demonstrating similar differences between conditions as observed in the results for overall discomfort.

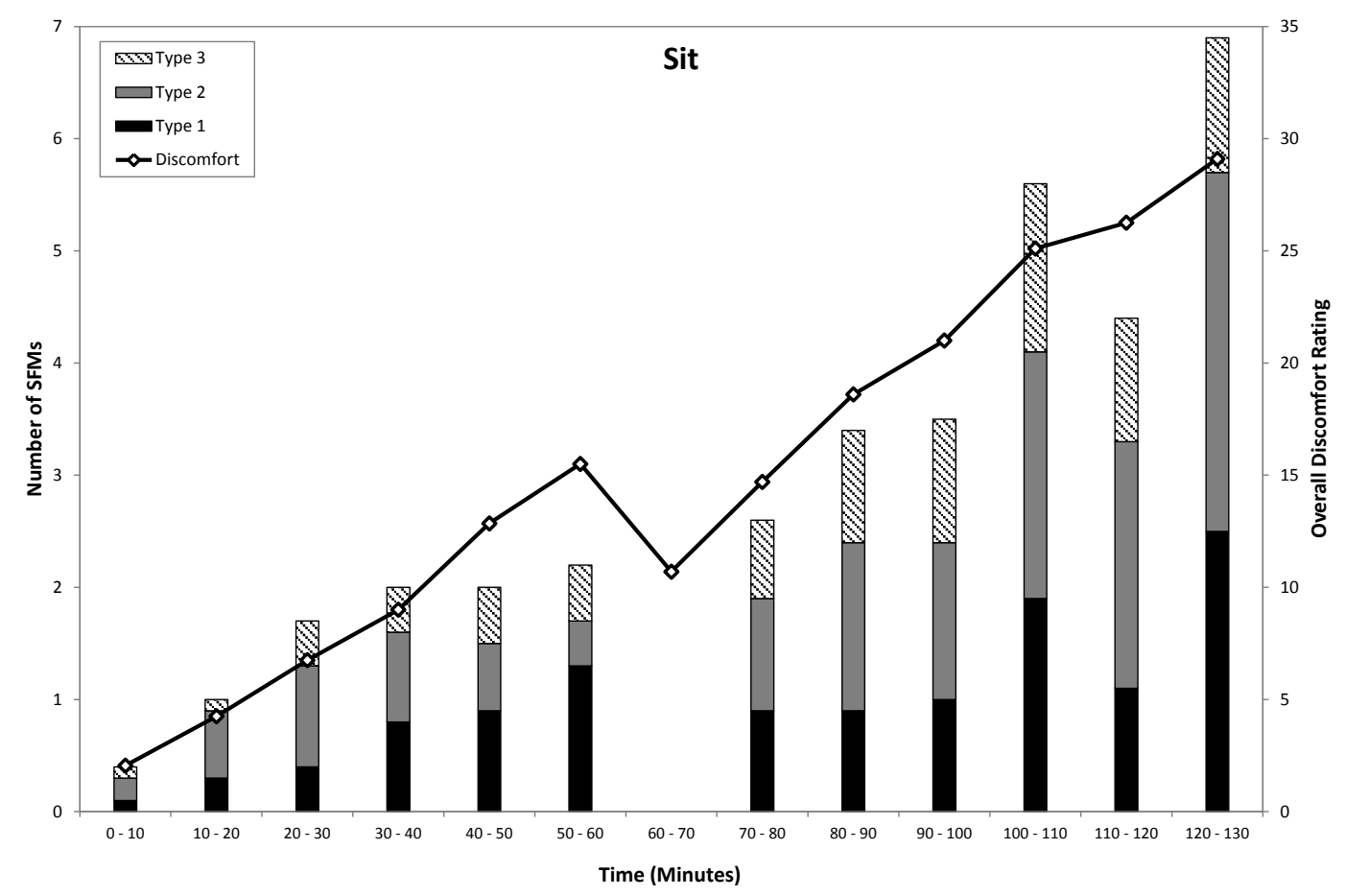

Figure 4: Mean overall discomfort ratings and number of SFMs over time for the 'Sit' condition 


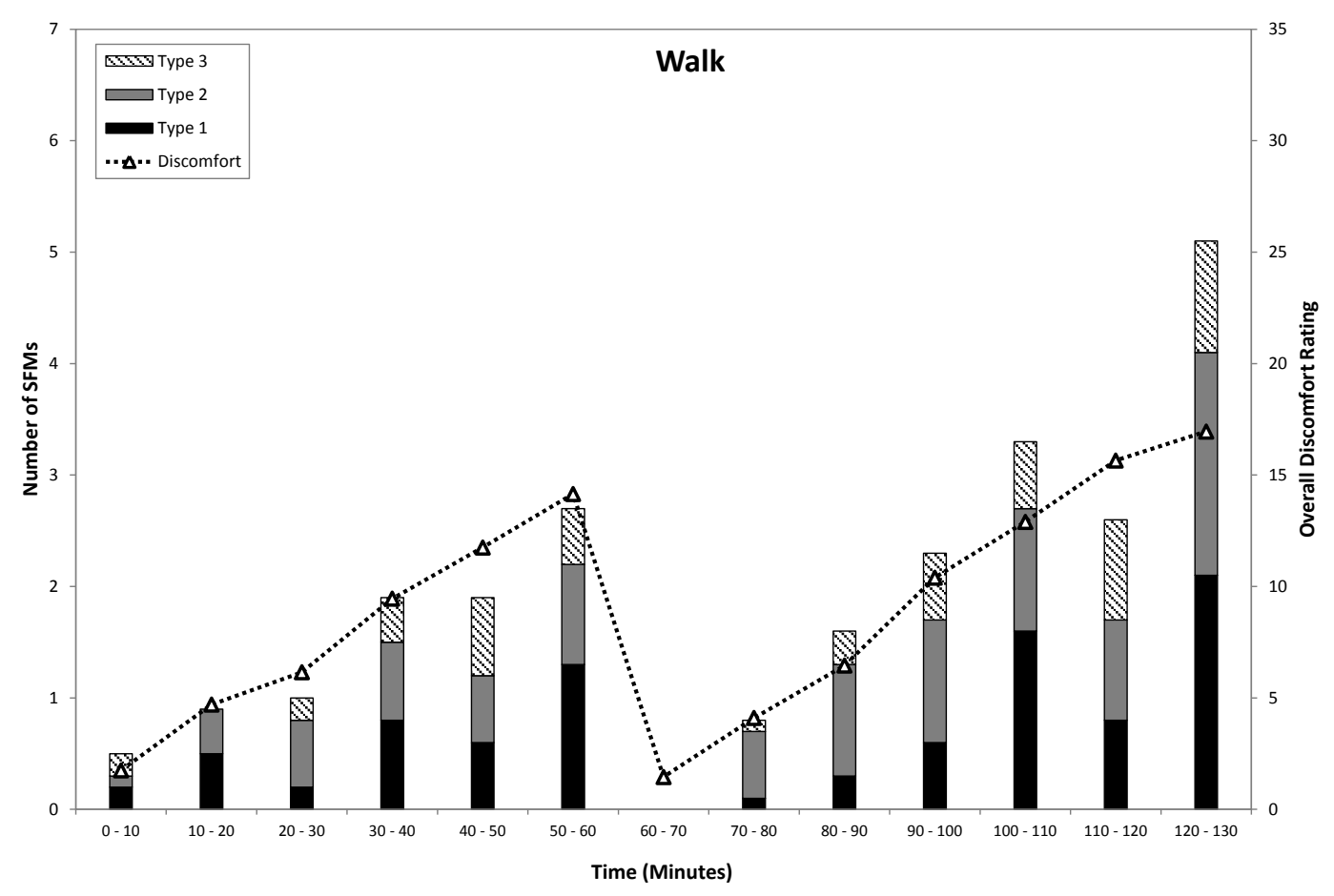

Figure 5: Mean overall discomfort ratings and number of SFMs over time for the 'Walk' condition

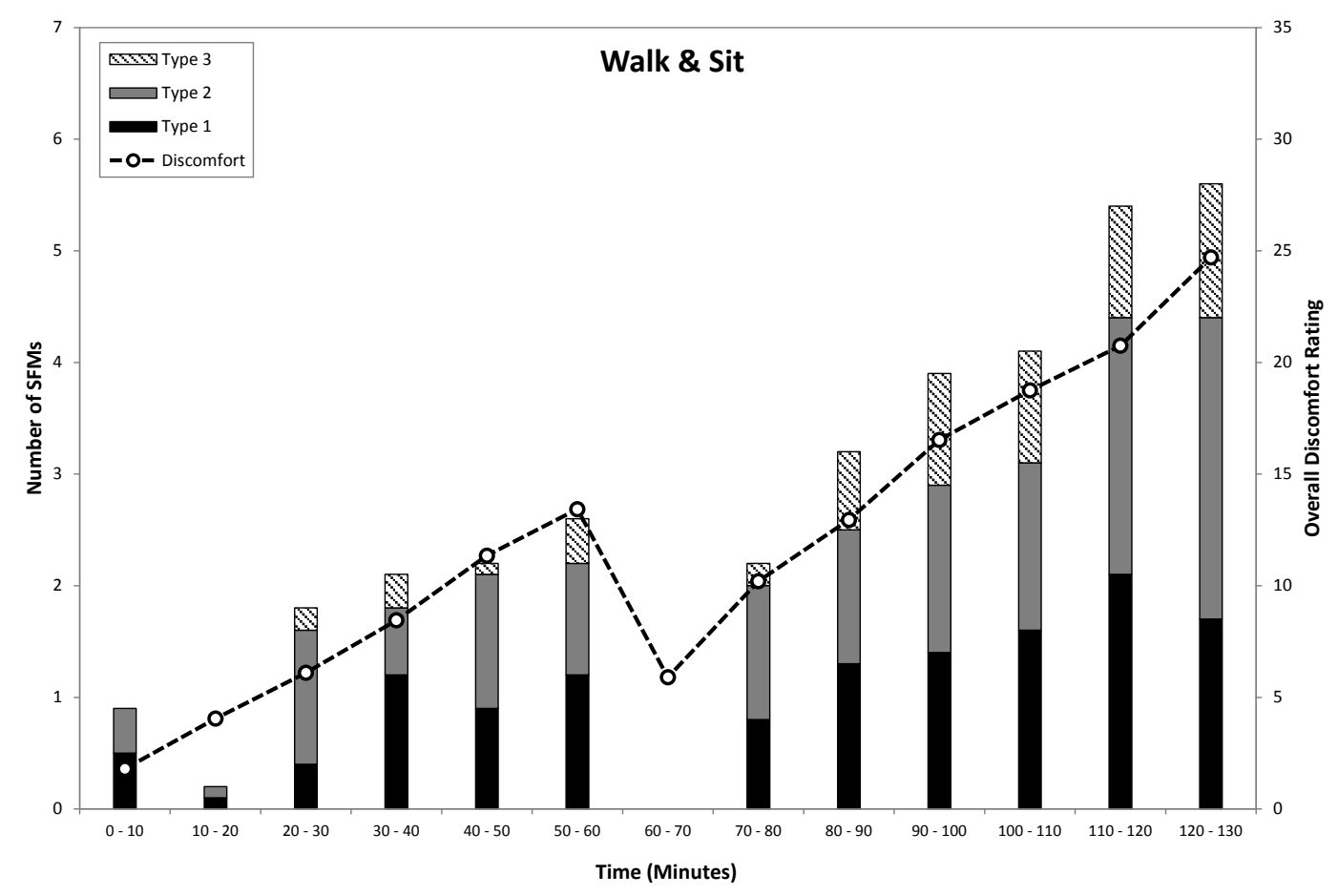

Figure 6: Mean overall discomfort ratings and number of SFMs over time for the 'Walk \& Sit' condition

Participants' SFMs show that each condition records very similar results for SFM frequency until 60 minutes of driving, supporting the findings of the subjective rating scales. No data was recorded during the breaks from driving due to the design of the study but a clear 
decrease in SFM frequency, or the number of SFMs, is observed when comparing the results for $50-60$ minutes and those for $70-80$ minutes in the 'Walk' condition. A smaller decrease is observed when comparing the same time intervals for the 'Walk \& Sit' condition, however an increase was observed in the 'Sit' condition.

When comparing the number of SFMs recorded between 120-130 minutes for each of the conditions, the greatest number of SFMs were recorded in the 'Sit' condition, 6.9, followed by the 'Walk \& Sit' condition, 5.6, with the fewest SFMs recorded in the 'Walk' condition, 5.1, again supporting the findings for overall discomfort (values are counts of SFMs in a 10 minute window).

\section{Discussion}

\section{Subjective Overall Discomfort}

During the first hour of exposure the participants' responses to the three conditions were identical, as was expected, as each condition had the same vibration stimulus and the same task (Mansfield, 2005). During this epoch, there was no significant difference in the results as each condition followed a similar trend (Figure 3), supporting the findings of the previous literature (Mansfield et al., 2014, Mansfield et al., 2015).

After 60 minutes, the mean overall discomfort reached a level corresponding with 'Little Discomfort' for all three conditions as shown in Table 2. This displays that no difference was found between conditions, but also that the method is reliable as the discomfort ratings recorded follow a similar trend when repeated. This is supported when examining the discomfort gradients for each of the conditions. Regression showed that the gradient for the 'Sit' condition was $0.26,0.24$ for the 'Walk' condition and 0.22 for the 'Walk \& Sit' condition. This implies that very little difference is observed during the first 60 minutes; differences between conditions occurred from the start of the break from the driving task until the end of trial.

\section{Breaks from the Driving Task}

During the break from the driving task there was an acute decrease in the discomfort ratings for all three conditions that was immediately measureable (i.e. at the 62 minute interval) 
and this decrease in discomfort continued throughout the following 8 minutes. Although the decrease in discomfort was observed in all three conditions, the effectiveness of the break from driving, or the amount of discomfort reduction, was dominated by the required activity during the break.

A much larger decrease in discomfort was observed after 2 minutes of the break in the 'Walk' condition. A mean decrease of 2.0 was observed in the 'Sit' condition, in comparison with a larger decrease of 6.7 in the 'Walk \& Sit' condition and an again larger decrease of 9.7 in the 'Walk' condition. This suggests that after just 2 minutes of walking, drivers have benefitted more, in terms of overall discomfort, than if they had sat in another chair for the duration of the 10-minute break or remained seated in the vehicle seat. Furthermore, although not as beneficial as walking; leaving the vehicle seat and sitting in another chair is more beneficial in terms of overall discomfort reduction than remaining seated in the vehicle. After 2 minutes of the break from driving, the 'Sit' condition recorded a mean overall discomfort rating that corresponds to 'Little Discomfort', the 'Walk \& Sit' condition recorded a mean overall discomfort rating that corresponds to 'Very Little Discomfort' and the 'Walk' condition recorded a mean overall discomfort rating that corresponds to 'Just Noticeable Discomfort' (Table 2).

Table 2: Mean overall discomfort rating and discomfort descriptor at each time interval for all 3 conditions

\begin{tabular}{|c|c|c|c|c|c|c|}
\hline & \multicolumn{2}{|c|}{ Sit } & \multicolumn{2}{|c|}{ Walk } & \multicolumn{2}{|c|}{ Walk \& Sit } \\
\hline $\begin{array}{c}\text { Time } \\
\text { (m) }\end{array}$ & $\begin{array}{c}\text { Discomfort } \\
\text { Rating }\end{array}$ & Descriptor & $\begin{array}{l}\text { Discomfort } \\
\text { Rating }\end{array}$ & Descriptor & $\begin{array}{c}\text { Discomfort } \\
\text { Rating }\end{array}$ & Descriptor \\
\hline 0 & 0.00 & $\begin{array}{l}\text { No } \\
\text { Discomfort at } \\
\text { all }\end{array}$ & 0.00 & $\begin{array}{l}\text { No Discomfort } \\
\text { at all }\end{array}$ & 0.00 & $\begin{array}{l}\text { No Discomfort } \\
\text { at all }\end{array}$ \\
\hline 2 & 0.00 & $\begin{array}{l}\text { No } \\
\text { Discomfort at } \\
\text { all }\end{array}$ & 0.10 & $\begin{array}{l}\text { No Discomfort } \\
\text { at all }\end{array}$ & 0.55 & $\begin{array}{l}\text { No Discomfort } \\
\text { at all }\end{array}$ \\
\hline 10 & 2.05 & $\begin{array}{l}\text { Just } \\
\text { Noticeable } \\
\text { Discomfort }\end{array}$ & 1.75 & $\begin{array}{l}\text { Just } \\
\text { Noticeable } \\
\text { Discomfort }\end{array}$ & 1.80 & $\begin{array}{l}\text { Just } \\
\text { Noticeable } \\
\text { Discomfort }\end{array}$ \\
\hline 20 & 4.25 & $\begin{array}{l}\text { Very Little } \\
\text { Discomfort }\end{array}$ & 4.70 & $\begin{array}{l}\text { Very Little } \\
\text { Discomfort }\end{array}$ & 4.05 & $\begin{array}{l}\text { Very Little } \\
\text { Discomfort }\end{array}$ \\
\hline 30 & 6.75 & $\begin{array}{l}\text { Very Little } \\
\text { Discomfort }\end{array}$ & 6.15 & $\begin{array}{l}\text { Very Little } \\
\text { Discomfort }\end{array}$ & 6.10 & $\begin{array}{l}\text { Very Little } \\
\text { Discomfort }\end{array}$ \\
\hline 40 & 9.00 & $\begin{array}{l}\text { Very Little } \\
\text { Discomfort }\end{array}$ & 9.45 & $\begin{array}{l}\text { Very Little } \\
\text { Discomfort }\end{array}$ & 8.45 & $\begin{array}{l}\text { Very Little } \\
\text { Discomfort }\end{array}$ \\
\hline
\end{tabular}




\begin{tabular}{|c|c|c|c|c|c|c|}
\hline 50 & 12.85 & $\begin{array}{l}\text { Little } \\
\text { Discomfort }\end{array}$ & 11.75 & $\begin{array}{l}\text { Little } \\
\text { Discomfort }\end{array}$ & 11.35 & $\begin{array}{l}\text { Little } \\
\text { Discomfort }\end{array}$ \\
\hline 60 & 15.50 & $\begin{array}{l}\text { Little } \\
\text { Discomfort }\end{array}$ & 14.15 & $\begin{array}{l}\text { Little } \\
\text { Discomfort }\end{array}$ & 13.43 & $\begin{array}{l}\text { Little } \\
\text { Discomfort }\end{array}$ \\
\hline 62 & 13.50 & $\begin{array}{l}\text { Little } \\
\text { Discomfort }\end{array}$ & 4.45 & $\begin{array}{l}\text { Just } \\
\text { Noticeable } \\
\text { Discomfort }\end{array}$ & 6.75 & $\begin{array}{l}\text { Very Little } \\
\text { Discomfort }\end{array}$ \\
\hline 70 & 10.70 & $\begin{array}{l}\text { Little } \\
\text { Discomfort }\end{array}$ & 1.45 & $\begin{array}{l}\text { Just } \\
\text { Noticeable } \\
\text { Discomfort }\end{array}$ & 5.90 & $\begin{array}{l}\text { Very Little } \\
\text { Discomfort }\end{array}$ \\
\hline 72 & 11.30 & $\begin{array}{l}\text { Little } \\
\text { Discomfort }\end{array}$ & 1.90 & $\begin{array}{l}\text { Just } \\
\text { Noticeable } \\
\text { Discomfort }\end{array}$ & 6.05 & $\begin{array}{l}\text { Very Little } \\
\text { Discomfort }\end{array}$ \\
\hline 80 & 14.70 & $\begin{array}{l}\text { Little } \\
\text { Discomfort }\end{array}$ & 4.10 & $\begin{array}{l}\text { Just } \\
\text { Noticeable } \\
\text { Discomfort }\end{array}$ & 10.20 & $\begin{array}{l}\text { Very Little } \\
\text { Discomfort }\end{array}$ \\
\hline 90 & 18.60 & $\begin{array}{l}\text { Moderate } \\
\text { Discomfort }\end{array}$ & 6.45 & $\begin{array}{l}\text { Very Little } \\
\text { Discomfort }\end{array}$ & 12.95 & $\begin{array}{l}\text { Little } \\
\text { Discomfort }\end{array}$ \\
\hline 100 & 21.00 & $\begin{array}{l}\text { Moderate } \\
\text { Discomfort }\end{array}$ & 10.40 & $\begin{array}{l}\text { Very Little } \\
\text { Discomfort }\end{array}$ & 16.53 & $\begin{array}{l}\text { Little } \\
\text { Discomfort }\end{array}$ \\
\hline 110 & 25.10 & $\begin{array}{l}\text { Moderate } \\
\text { Discomfort }\end{array}$ & 12.90 & $\begin{array}{l}\text { Little } \\
\text { Discomfort }\end{array}$ & 18.75 & $\begin{array}{l}\text { Moderate } \\
\text { Discomfort }\end{array}$ \\
\hline 120 & 26.25 & $\begin{array}{l}\text { Moderate } \\
\text { Discomfort }\end{array}$ & 15.65 & $\begin{array}{l}\text { Little } \\
\text { Discomfort }\end{array}$ & 20.75 & $\begin{array}{l}\text { Moderate } \\
\text { Discomfort }\end{array}$ \\
\hline 130 & 29.10 & $\begin{array}{l}\text { Moderate- } \\
\text { High } \\
\text { Discomfort }\end{array}$ & 16.95 & $\begin{array}{l}\text { Little } \\
\text { Discomfort }\end{array}$ & 24.70 & $\begin{array}{l}\text { Moderate } \\
\text { Discomfort }\end{array}$ \\
\hline
\end{tabular}

A further similar decrease is observed in all three conditions by the end of the break from the driving task where participants recorded a mean discomfort rating of 1.45 for the 'Walk' condition; less than the discomfort recorded after 10 minutes of driving. This suggests that on average, drivers will have almost returned to the discomfort at which they began the drive after a break of walking for 10 minutes. It can be considered that the discomfort rating is 'reset' with 10 minutes of walking.

The decrease in overall discomfort was less in the 'Walk \& Sit' condition as participants' discomfort decreased to an average of 5.9, similar to the average overall discomfort rating recorded after about 30 minutes of driving. It can be considered that discomfort is improved but not 'reset' with 10 minutes of taking break from driving, leaving the seat but remaining seated in another seat. The decrease in overall discomfort is less still in the 'Sit' condition as participants' discomfort rating decreased to an average of 10.7 , similar to the average 
overall discomfort rating recorded after about 45 minutes of driving. Again, it can be considered that discomfort is slightly reduced but not 'reset' with 10 minutes of taking a break from driving but not leaving the vehicle seat.

At 62 minutes a repeated measures ANOVA determined that mean discomfort ratings differed with statistical significance between conditions $(F(1.581,14.231)=24.740, p<$ 0.05). Post hoc tests using a Bonferroni correction revealed that participants benefitted more in terms of discomfort reduction by leaving the vehicle as the reduction was shown to be significant when comparing the 'Sit' condition with the 'Walk' condition and the 'Walk \& Sit' condition $(p<0.001)$.

Comparing the 'Walk' condition and the 'Walk \& Sit' condition at 62 minutes, no statistical difference was found $(p=0.438)$. However, it should be noted that both of these conditions involved an initial dismount from the driving simulator and a nominally identical walk to either the treadmill or chair for the 'sit' condition.

At 70 minutes another repeated measures ANOVA determined that mean discomfort ratings differed statistically significantly between conditions $(F(1.393,12.535)=22.729, p<0.05)$. Post hoc tests using a Bonferroni correction revealed that participants benefitted more in terms of discomfort decrease by leaving the vehicle seat as the reduction in discomfort was shown to be statistically significant when comparing the 'Sit' condition with the 'Walk' and 'Walk \& Sit' conditions ( $p<0.001$ for both comparisons). Furthermore, when comparing the 'Walk' condition and the 'Walk \& Sit' condition at 70 minutes, at statistical difference was found $(p<0.05$ ) implying that participants benefitted significantly in terms of discomfort decrease by walking for 10 minutes in comparison with sitting in another seat. Therefore it can be concluded that at 70 minutes, or after 10 minutes of a break from driving, drivers will experience a significant reduction in discomfort by leaving the vehicle in comparison to remaining seated in the vehicle seat. Furthermore, the behaviour or activity undertaken after leaving the vehicle also has a significant effect on discomfort decrease as drivers who walk for 10 minutes will experience a significantly greater benefit in comparison with drivers who leave the vehicle but sit in another seat.

The reduction in overall discomfort observed during the 'Walk' condition holds some similarities to the effects observed in Yonekawa et al. (1998) where TTS was 'reset' after 10 minutes rest from vibration exposure and also Ravnik et al. (2008) where driver discomfort 
was reduced to nearly zero after a 15 minute break after 100 minutes of driving. During this experiment it was observed that overall discomfort was 'reset' following 10 minutes of walking during a rest from vibration exposure.

\section{Rate of Discomfort Onset upon Returning to the Driving Task}

When returning to the driving task, discomfort increased with duration of driving for all three conditions, with similar trends to those observed for the first 60 minutes of the trial. A steady increase is recorded in all three conditions between $70-130$ minutes. Regression lines (shown in Figure 3) showed that for the first 60 minutes the gradient was 0.26 for the 'Sit' condition, 0.24 for the 'Walk' condition and 0.22 for the 'Walk \& Sit' condition. During the second hour of driving, the gradient for the 'Walk' condition was 0.27 , and therefore the rate of change in discomfort remained similar to that of the first hour of driving. However, the gradient for the 'Sit' condition and the 'Walk \& Sit' condition increased to both 0.30 for both conditions. This shows that there was a more rapid change in discomfort for the second hour of driving for these conditions despite the fact that discomfort started at a higher level at the end of the break.

It is clear from the results that participants recorded significantly lower overall discomfort ratings in the 'Walk' condition after the break from driving and the benefits were observed until the end of the trial. On average, at 130 minutes participants recorded an overall discomfort rating of 17.0 in the 'Walk' condition in comparison with a mean overall discomfort rating of 24.7 in the 'Walk \& Sit' condition and 29.1 in the 'Sit' condition. When correlated with the discomfort descriptors, these discomfort ratings correspond to 'Little Discomfort' for the 'Walk' condition, 'Moderate Discomfort' for the 'Walk \& Sit' condition and 'Moderate-High Discomfort' for the 'Sit' condition.

The ANOVA completed for the data at the end of the trial determined that mean discomfort ratings differed between conditions $(F(1.1 .432,12.885)=31.483, p<0.05)$. Post hoc tests using the Bonferroni correction revealed that participants recorded significantly lower overall discomfort ratings upon completing the trial in the conditions where they were required to leave the vehicle seat in comparison with remaining seated in the vehicle seat as a significant difference was observed when comparing the 'Sit' condition with the 'Walk \& Sit' condition $(p<0.05)$ and the 'Walk' condition $(p<0.001)$. This suggests that participants' overall discomfort rating at the end of the 130-minute drive was significantly reduced due to 
the participant leaving the vehicle seat during the break from driving. Furthermore, a significant difference was also observed when comparing the 'Walk \& Sit' condition and the 'Walk' condition $(p<0.001)$. This suggests that participants benefitted, in terms of discomfort reduction, significantly from walking for 10 minutes during the break from driving in comparison with sitting in another seat, even after completing a further 60 minutes of driving.

Subjective discomfort data implies that when taking a break from a long-term drive, drivers' comfort will benefit more from leaving the vehicle than remaining seated in the vehicle seat. Furthermore, upon leaving the vehicle, drivers will benefit more from taking a 10-minute walk than leaving the vehicle and sitting in another seat. This has implications for drivers planning to undertake a long duration drive: drivers should plan breaks at regular intervals in order to reduce discomfort during and at the end of the journey. Drivers should aim to adapt their behaviour during breaks in order to gain the full benefit in terms of discomfort reduction, with a planned 10-minute walk. As stated previously, the guidelines for drivers undertaking a long-term drive suggest that a break of 15 minutes should be implemented every 2 hours (Department for Transport, UK); however these guidelines are focused on safety rather than comfort (Horne \& Reyner, 1999). It may be of benefit for the findings to be incorporated into any future guidelines, as there is the possibility that the benefits in terms of comfort improvement may encourage drivers to adhere to the guidelines and the importance of activity or behaviour during breaks should be well defined.

There may be wider implications for these findings, outside of non-commercial driving. Drivers who drive for extended durations as part of their job may find that taking effective breaks from driving may have added positive effects. The negative health effects associated with long term driving have been well documented. It has been established that drivers who drove extended durations and distances as part of their job 'always' or 'often' experienced lower back discomfort during driving (Gyi \& Porter, 1998) and furthermore, commuters who travelled distances of over 25, 000 kilometres per year missed on average, 24.4 days of work per year due to prolonged driving (Porter \& Gyi, 2002). If implementing breaks during long duration driving can aid in reducing the discomfort experienced then this may have a positive impact on employee attendance and well-being. 
Drivers working in industries where they are exposed to much greater magnitudes of vibration, when compared with normal road driving, as part of their job may benefit substantially from breaks from driving and vibration exposure. Vibration magnitude has been shown to increase the rate of change in discomfort (Mansfield et al., 2014, Mansfield et al., 2015) and drivers working with heavy machinery may be placed at a lesser risk of developing negative symptoms associated with long term exposure to vibration if breaks with effective behaviour can be implemented into their work schedule.

\section{Seat Fidgets and Movements}

The findings of the previous study by Sammonds et al. (2017) established that SFM frequency is shown to increase with duration of driving and that a close relationship is observed between SFM frequency and subjective ratings of overall discomfort. The results of this study support these findings as SFM frequency is shown to increase with duration of driving in all 3 conditions in correspondence with the overall discomfort ratings reported.

SFM frequency increased between $0-60$ minutes for each of the conditions but the numerical data for these were very similar. The mean number of SFMs per 10 minutes increased from 0.4-0.9 between $0-10$ minutes to 2.2-2.7 between $50-60$ minutes for the three conditions ( $p<0.05$, two-tailed T-test). Each individual participant recorded an increase in the number of SFMs recorded between $50-60$ minutes when compared with the number of SFMs recorded between $0-10$ minutes for each of the conditions.

Upon returning to the driving task after the 10-minute break from driving, SFM frequency again showed an increase with duration of driving, but with significant differences between the conditions. Comparing the 70-80 minute window to the $120-130$ minute window, the mean number of SFMs per 10 minutes increased from 2.6 to 6.9 for the 'Sit' condition, from 0.8 to 5.1 for the 'Walk' condition and from 2.2 to 5.6 for the 'Walk \& Sit' condition. Each individual participant recorded a greater number of SFMs during the last 10 minutes of each trial when compared with the number of SFMs recorded between $70-80$ minutes, for each condition.

There were a number of limitations with the study, largely related to the fact that the study was conducted in a laboratory setting and future research should aim to explore how the results are affected when conducting a field trial. Different discomfort responses may be 
observed when the break is conducted in a different environment, and for naturalistic driving. For example, outside air, walking in a forest or seeing plants could further reduce discomfort (Park et al., 2010) when compared to walking on a treadmill or, alternatively, discomfort may be increased by the presence of unwanted noise (Mansfield, 2005). Additionally, the duration for which participants were required to drive and take a break for were fixed during this experiment. Further research should aim to investigate the relationship between rest and driving durations in terms of comfort in order to establish the optimal driving - rest combinations.

\section{Conclusions}

Subjective discomfort was shown to decrease during a break from a long-term drive on a driving simulator. Breaks from driving were beneficial regardless of the activity undertaken. The observed improvements in discomfort during breaks continued throughout the following 60 minutes of driving. Assuming that discomfort would continue to increase at a similar rate if a break had not been taken (Sammonds et al. 2017; Sammonds, 2016), by taking a break drivers actively reduced the total discomfort experienced upon completion of the drive. Breaks mid-drive can improve comfort at the end of the drive.

The type of activity performed whilst taking a break from a long-term drive has a large influence on the effectiveness of the break, both immediately and at the end of the drive. The results of this study determined that drivers who leave the vehicle seat would benefit significantly in terms of discomfort reduction than those who remain in the vehicle seat. Furthermore, drivers are recommended to take a 10 minute walk, rather than sit in another seat (e.g. coffee shop) when taking a break from a long-term driving.

A strong positive correlation was observed between subjective overall discomfort ratings and seat fidget and movement (SFM) frequency. Drivers were shown to move more frequently with duration of driving as discomfort increased, despite the differences in conditions. It can be concluded that the objective measure of SFMs has been shown to be successful in evaluating discomfort and that both subjective and objective measurements of discomfort are influenced by implementing breaks during a long-term drive.

\section{Competing interests and funding}

The authors have no competing interests. There was no external funding for this study. 


\section{Authors' contributions}

GS carried out the laboratory work, completed the majority of the data analysis, participated in the design of the study and drafted the manuscript. NM conceived the study, designed the laboratory, and worked with GS on the experimental design and analysis, and finalised the manuscript. MF worked with GS and NM on experimental design and drafting the manuscript.

\section{References}

Bazley, C. and Vink, P., 2016. Don't forget time in environmental design1. Work, 54(4), pp.1025-1029.

Borg, E., \& Borg, G. (2002). A comparison of AME and CR100 for scaling perceived exertion. Acta Psychologica, 109(2), 157-175.

Dunstan DW, Kingwell BA, Larsen R, et al. (2012) Breaking Up Prolonged Sitting Reduces Postprandial Glucose and Insulin Responses. Diabetes Care, (5):976-983. doi:10.2337/dc111931.

Franz, M., Durt, A., Zenk, R. and Desmet, P.M.A., 2012. Comfort effects of a new car headrest with neck support. Applied Ergonomics, 43(2), pp.336-343.

Gyi, D. E., \& Porter, J. M. (1998). Musculoskeletal problems and driving in police officers. Occupational Medicine, 48(3), 153-160.

Hiemstra-van Mastrigt, S., Meyenborg, I. and Hoogenhout, M., 2016. The influence of activities and duration on comfort and discomfort development in time of aircraft passengers. Work, 54(4), pp.955-961.

Horne, J. A., \& Reyner, L. A. (1995). Driver sleepiness. Journal of sleep research, 4(2), 23-29.

Horne, J. A., \& Reyner, L. A. (1999). Vehicle accidents related to sleep: a review. Occupational and environmental medicine, 56(5), 289-294.

Hu, F.B., Li, T.Y., Colditz, G.A., Willett, W.C. and Manson, J.E., 2003. Television watching and other sedentary behaviors in relation to risk of obesity and type 2 diabetes mellitus in women. Journal of the American Medical Association, 289(14), pp.1785-1791.

International Organization for Standardization. (1997). Mechanical vibration and shock Evaluation of human exposure to whole-body vibration: Part 1 - General requirements. ISO2631-1.

Kolich, M., \& Taboun, S. M. (2004). Ergonomics modelling and evaluation of automobile seat comfort. Ergonomics, 47(8), 841-863. 
Kuijt-Evers, L. F. M., Krause, F., \& Vink, P. (2003). Aspects to improve cabin comfort of wheel loaders and excavators according to operators. Applied Ergonomics, 34(3), 265-271.

Kyung, G., Nussbaum, M. A., \& Babski-Reeves, K. (2008a). Driver sitting comfort and discomfort (part I): Use of subjective ratings in discriminating car seats and correspondence among ratings. International Journal of Industrial Ergonomics, 38(5), 516-525.

Kyung, G., \& Nussbaum, M. A. (2008b). Driver sitting comfort and discomfort (part II): Relationships with and prediction from interface pressure. International Journal of Industrial Ergonomics, 38(5), 526-538.

Mansfield, N. J. (2005). Human response to vibration. CRC Press.

Mansfield, N. J., Mackrill, J., Rimell, A. N., \& MacMull, S. J. (2014). Combined effects of longterm sitting and whole-body vibration on discomfort onset for vehicle occupants. ISRN automotive engineering, 2014.

Mansfield, N., Sammonds, G., \& Nguyen, L. (2015). Driver discomfort in vehicle seats-Effect of changing road conditions and seat foam composition. Applied ergonomics, 50, 153-159.

Park, B.J., Tsunetsugu, Y., Kasetani, T., Kagawa, T. and Miyazaki, Y., 2010. The physiological effects of Shinrin-yoku (taking in the forest atmosphere or forest bathing): evidence from field experiments in 24 forests across Japan. Environmental health and preventive medicine, 15(1), pp.18-26.

Porter, J. M., \& Gyi, D. E. (2002). The prevalence of musculoskeletal troubles among car drivers. Occupational medicine, 52(1), 4-12.

Ravnik, D., Otáhal, S., \& Dodič Fikfak, M. (2008). Using different methods to assess the discomfort during car driving. Collegium antropologicum, 32(1), 267-276.

Sammonds, G. (2016). An Objective Measure to Quantify Discomfort in Long Duration Driving. PhD Thesis, UK: Loughborough University.

Sammonds, G., Fray, M., \& Mansfield, N.J. (2017) Effect of Long Term Driving on Driver Discomfort and its Relationship with Seat Fidgets and Movements (SFMs), Applied Ergonomics, 58, 119-127.

Yonekawa, Y., Maeda, S., Morioka, M., Kanada, K., \& Takahashi, Y. (1998). Prediction of TTS for hand intermittent vibration. Industrial health, 36(2), 191-196.

Zenk, R., Franz, M., Bubb, H. and Vink, P., 2012. Technical note: Spine loading in automotive seating. Applied ergonomics, 43(2), pp.290-295. 
